\title{
Caracterización de Algunos estilos locales de la Costa Central a inicios del Intermedio Tardío
}

\author{
Camilo Dolorier *
}

Lyda Casas Salazar**

\section{Resumen}

El presente estudio busca caracterizar alguno de los componentes cerámicos propios de la fase Ichma Inicial, para ello se emplea exclusivamente parámetros clasificatorios de orden estilístico, con miras a establecer categorías confrontables y contrastables. Consideramos que a este punto aun es necesario crear herramientas metodológicas apropiadas para lograr resultados explicativos de mayor alcance y precisión.

En este proceso se observa que en la conformación de los diversos estilos que componen el complejo estilístico denominado Ichma Inicial, intervienen tanto factores internos como externos. Cada uno de ellos presenta distinto grado y modo de penetración e influencia. En segunda instancia se puede apreciar que los estilos no se organizan del mismo modo. Tanto así, que forma y decoración (donde se observan elementos ligados a la técnica, composición y diseño), pueden presentar cada uno de ellos un movimiento independiente, y responder a tradiciones estilísticas no emparentadas con formas particulares de organización.

El estudio estilístico nos permitió distinguir la presencia de estilos decorativos estables donde forma y decoración crean unidades. De otro lado, tenemos a los estilos morfológicos estables sin decoración. Finalmente los estilos decorativos "transgresores", que suelen irrumpir transversalmente en varias unidades morfológicas distintas en simultáneo.

\section{Palabra Clave}

Huallamarca, Ichma Inicial, estilos transgresores, estilo Anaranjado Ornamental, estilo Aquillado, estilo Crema Chorreado, estilo Tricolor Geométrico.

\begin{abstract}
This study aimed to characterize some of the ingredients typical of the ceramic phase Ichma Beginner, it is used exclusively for qualifying order stylistic parameters, to establish categories confrontations and contrasts. We believe that this is even necessary to create appropriate methodological tools to achieve results of greater explanatory scope and accuracy.

In this process shows that the conformation of the different styles that make up the complex stylistic Ichma called Initial, involving both internal and external factors. Each has a different degree and mode of penetration and influence. In the second instance can be seen that the styles are not organized the same way. So much so that the form and decoration (where there are elements associated with the technique, composition and design), may each of them an independent movement, and to no stylistic traditions related to particular forms of organization.

The study allowed us to distinguish the style of decorative styles and decoration forming stable units created. Moreover, we have a stable morphological style without decoration. Finally decorative styles "offenders", which often break transversely into several distinct morphological units simultaneously.
\end{abstract}

\section{Keyword}

Huallamarca, Ichma Initial, transgressors styles, Orange Ornamental Style, Aquillado Style, Cream Blast Style, Geometric Tricolor Style.

\footnotetext{
* Universidad Nacional Mayor de San Marcos. Correo electrónico: camilo_dolorier@yahoo.com

** Directora del Museo de Sitio Huallamarca. Correo electrónico: lyda_casas@yahoo.com.ar
} 


\section{INTRODUCCIÓN}

El estudio de los estilos tardíos de la costa central ha cobrado notable interés en los últimos tiempos. Al descuido inicial fundamentado en el poco atractivo estético de los materiales, en lo desprolijo de la manufactura y relativa simpleza de su decoración, se sumó la incesante destrucción de asentamientos arqueológicos producto de la expansión urbana. Afortunadamente hoy se comienza a revalorizar la cultura local e identidad limeña prehispánica, y para ello, se plantean investigaciones de distinto género y alcance. Por un lado se elaboran campañas de recopilación del dato empírico, generalmente realizadas de forma fortuita y organizadas dentro de programas de saneamiento urbano (estudios de evaluación e impacto arqueológico). Y del otro lado, se efectúan estudios programados en base a problemáticas de investigación y se abordan tanto trabajos de campo como de archivo.

En este contexto, desde el Museo de Sitio de Huallamarca emprendemos el estudio de los diarios de campo de los "trabajos de restauración limpieza y rescate de especimenes arqueológicos en la Huaca Pan de Azúcar o Huallamarca”, realizados entre el 10 de febrero al 31 de octubre de 1958. Luego de casi 50 años de efectuado el registro emprendemos el reto de clasificar estilísticamente los diversos componentes alfareros asociados a un conjunto de 49 tumbas y demás especímenes descontextualizados procedentes de dicha excavación arqueológica.

Los trabajos de restauración aludidos fueron originalmente solicitados por la Municipalidad de San isidro y ejecutados por la Dirección de Arqueología e Historia del Ministerio de Educación Pública. Dichas labores le fueron encomendadas al Dr. Arturo Jiménez Borja como director, pero en campo se desempeñaron en primera instancia el arqueólogo Francisco Iriarte Brenner (entre el 10 de febrero y el 13 de marzo de 1958), y una segunda etapa el Sr.
Jorge Zegarra Galdos entre el 14 de marzo al 31 de octubre). El Sr. Jorge Zegarra fue funcionario público, estupendo dibujante y hombre de campo con amplia experiencia en la intervención de sitios arqueológicos. Él desarrolló la mayor parte del registro de campo, sus descripciones son pormenorizadas y los gráficos de gran valor documental. Al no ser un arqueólogo de formación descuidó mucho del registro técnico, consideraciones cronológicas y observaciones interpretativas. Sin embargo, es preciso abonar en su favor al señalar que su experiencia de campo le permitió identificar y aislar adecuadamente los contextos funerarios que se le presentaron a lo largo del trabajo. El cuidado que dedicó a la descripción de los materiales, así como su ubicación referencial, nos hizo posible reconstruir adecuadamente los contextos y sistematizar parte de la información que hoy presentamos.

El resumen de los trabajos nos presenta un sitio complejo con dos ocupaciones bien definidas. La primera ocupación hace referencia a un edificio piramidal elaborado con adobitos en forma de "granos de maíz". Este gran edificio público pertenecería a la parte inicial del Intermedio Temprano que luego de su abandono sería reutilizado como cementerio.

La segunda ocupación muestra dos componentes funerarios. Existe un pequeño núcleo de entierros extendidos acompañados por material alfarero de los estilos Lima Tardío y Nievería. Junto a ellos un nutrido grupo de fardos funerarios con falsa cabeza, que revelan un modo de enterramiento asignado por la mayoría de autores como correspondientes a la parte final del Horizonte Medio (HM) e Inicios del período Intermedio Tardío (PIT). Este lapso de tiempo atañe a lo que se suele denominar Ichma Inicial o Temprano.

Como ya advertimos por el título, centraremos nuestra investigación principalmente en el estudio de los estilos cerámicos correspondientes al denominado Ichma Inicial. 


\section{ANTECEDENTES DEL ICHMA INICIAL}

Hasta la década del 90 la cronología y estilos tardíos del Rímac no habían sido trabajados en forma consistente, salvo algunos pocos reportes como los de Stumer (1954) e Iriarte (1960), y estudios complementarios para los valles del Chillón y Lurín (Ludeña 1975; Pérez y Arce 1989; Bonavía 1959; y Lavallee 1965-66 respectivamente), la preocupación y sistematización de los estilos del PIT se hallaba aun ausente. En este contexto Bazán (1991), plantea en su tesis de licenciatura una discusión acerca de la terminología utilizada hasta el momento y una ordenación secuencial de los materiales.

Bazán propuso la primera secuencia estilística de los períodos tardíos trabajada con materiales del Rímac y correlacionada con los dos valles adyacentes. Definió los estilos Ichma Inicial e Ichma Medio y el Ichma Fitomorfo del HM 4b, de una colección de vasijas halladas en la explanada y sobre los muros de la Huaca Santa Catalina. Por su parte el Ichma Medio del PIT fue definido sobre la base de material procedente de Pachacamac, Huaquerones, Huaca Cruz de Armatambo y de bibliografía, principalmente fragmentería asociada a las pirámides con rampa.

La secuencia estilística propuesta por Bazán aun despierta polémica, sin embargo fue la primera propuesta para ordenar material disperso y en acuñar el término Ichma (en reemplazo de Huancho) para dicho material y componente social.

Casi una década más tarde Guerrero (2004) compara contextos funerarios de distinto lugares en el Rímac como Huallamarca, Rinconada y Armatambo. Con ellos propone una cronología cerámica y de patrones funerarios que serían representativos de la sociedad Ychma. Según él, en Huallamarca se hallaría la fase más temprana del denominado Ychma Inicial.

Para Guerrero los orígenes del estilo Ychma se pueden encontrar en el Horizonte Medio
2-3. Mientras que a fines del HM aparecerían diversos elementos que señalarían la existencia de una fuerte relación estilística entre las zonas de Huaral-Huacho y Rímac-Pachacamac.

La cerámica derivada del HM 2, presenta plumas, cruces con círculo central, bandas cremas, guiones, semicírculos concéntricos pendientes de los bordes y líneas ondulantes con puntos negros como gusanos. A fines del HM es frecuente encontrar también piezas similares al Tricolor Geométrico de Chancay en Ancón y Huallamarca.

En el PIT surge una mayor regionalización de estilos, contacto con grupos serranos y aparecen piezas de intercambio del estilo Cuculí. A esta época corresponderían cántaros cara gollete, decoración de puntos en zona y piel de ganso. Desaparecen los círculos pendientes, y se populariza la banda crema descuidada, piezas de color negro y vasijas llanas de mala calidad.

De otro lado, para Vallejo (Vallejo 1998, 2004) la cerámica de fines del HM está representada por el estilo Huaura (estudiado en materiales de la zona), cuya influencia para los valles vecinos habría sido tan fuerte que a partir de allí habrían surgido los estilos locales del PIT, como el Chancay y el Ychsma. Por su parte el estilo Tricolor Geométrico sería la base para la formación del estilo Chancay Negro sobre Crema.

En su secuencia cerámica la fase Ychsma Temprano A (YT-A) empieza con el inicio del Período Intermedio Tardío (PIT), pues, precisamente los orígenes del estilo Ychsma se encontrarían a finales del HM 4. Los contextos funerarios más característicos del YT-A serían los de Huallamarca, donde en varios contextos se apreciarían elementos pertenecientes tanto a una u otra época. Materiales de esta fase habrían sido hallados también en Pachacamac y en Ancón.

Vallejo señala que a nivel morfológico y decorativo el YT-A se basa todavía en una gran 
diversidad de formas, tanto de tipos decorados como los no decorados.

La decoración más típica se halla en el tercio superior del cuerpo y cuello, y consistiría en bandas oblicuas alternadas con puntos de color negro y blanco, pequeños semicírculos con puntos negros en el borde de las vasijas. Los colores serían rojo, blanco y negro; acabado mate; desaparece el pulido; aplicación descuidada de pintura; imperfección en la ejecución de trazos y motivos.

\section{Metodología}

Para el estudio de los estilos cerámicos empleamos dos fuentes distintas: material de archivo y material de depósito. Dentro del material de archivo consideramos exclusivamente el referido a las descripciones y dibujos elaborados por Jorge Zegarra en su diario de campo. Los dibujos fueron digitalizados y redibujados en un programa de diseño gráfico, luego, en función de las descripciones fueron puestos a escala, proporción y se le incorporaron detalles decorativos en color. Cada pieza fue organizada en primera instancia según su contexto arqueológico de procedencia y luego fue definida y clasificada bajo preceptos exclusivamente estilísticos. Así se obtuvo el registro y clasificación de 270 piezas asociadas a 49 contextos funerarios y junto a ellas se estudiaron otras 180 vasijas aproximadamente, que fueron recogidas del relleno sin asociación clara. A pesar de la gran cantidad de material no asociado que empleamos en esta clasificación, es necesario señalar que la mayor parte del corpus utilizado presenta una coherencia cronológica y estilística.

El segundo tipo de fuente empleada corresponde al material cerámico custodiado por el museo de sitio de Huallamarca, buena parte de ellos proviene de las excavaciones realizadas por Zegarra y aun es posible confrontar los registros e identificar las vasijas dibujadas en el diario de campo. A este respecto cabe destacar la calidad de los dibujos de Zegarra que al ser confrontados con la realidad objetiva presentan muy pocas diferencias. Otra parte del lote utilizado que nos permitió comparar y complementar apuntes y descripciones (mas no dibujos), es el correspondiente a la colección de las excavaciones arqueológicas realizadas entre 1991-92 por Valladolid, y que se encuentran en los depósitos del museo.

Nuestro trabajo consistió en ordenar y clasificar este corpus aparentemente caótico en categorías estilísticas bien definidas, susceptibles de comparación y verificación. Vimos la necesidad de proveernos de herramientas fiables, comprendiendo los elementos componentes en su unicidad y organicidad. Para ello creímos necesario prescindir del análisis tipológico y tecnológico (común a este tipo de estudios) y utilizar el estudio estilístico. Con esto buscamos integrar bajo un mismo parámetro componentes morfológicos, de diseño y decorativos.

Considerando que los elementos estilísticos no se distribuyen unitariamente, al azar, ni carentes de orden, asumimos que en un estado natural debería existir una relación directa entre conjuntos morfológicos (formas alfareras específicas) y una determinada clase de diseños y decoración. En efecto, el estudio estilístico nos permitió distinguir que algunos modos decorativos se asocian casi exclusivamente con determinados géneros morfológicos alfareros, conformando una suerte de estilos decorativos estables con normas y cánones bien definidos. De otro lado, que existen géneros morfológicos complejos, compuestos por elementos formales que al intercambiarse generan variabilidad sin por ello perder su identidad, determinando estilos morfológicos estables sin decoración. Finalmente identificamos la presencia de estilos de carácter exclusivamente decorativos, que no se asocian con una forma exclusiva de vasija sino con un conjunto amplio de formas pertenecientes a distintos estilos morfológicos. A estos los hemos 
denominado estilos decorativos o "transgresores", pues suelen irrumpir transversalmente en varias unidades morfológicas en simultáneo. $\mathrm{Al}$ intruir forman variabilidad dentro del estilo morfológico de origen sin por ello generar uno nuevo.

A este respecto encontramos una variedad de estilos clasificados como estilos decorativos estables, que relacionan componentes morfológicos y decorativos (estilos Hualla o Inciso Punzonado y Anaranjado Ornamental). Luego los estilos morfológicos estables, que emplea categorías exclusivamente morfológicas, sin decoración (estilo Aquillado). Finalmente los estilos decorativos o transgresores que presentan variables tecnológicas o decorativas sobre formas variadas. (estilos Crema Chorreado, Negro sobre Crema, Amarillo Pálido y Negro Pulido,).

\section{CARACTERIZACión de Algunos estilos AlFARE- ROS IDENTIFICADOS EN HuallamarCA}

\section{Estilo Hualla o Inciso Punzonado en franjas.}

Luego de un examen minucioso de los elementos formales del estilo, advertimos que se puede caracterizar a partir de cuatro componentes estrechamente interconectados: incisión y puntos, característica de diseño, forma y baño amarillo pálido. Así, observamos que producto de su combinación origina un estilo estable y coherente en formas y contenidos. Se aprecia una organización con parámetros y cánones estilísticos claros cuando no rígidos.

En primer lugar resaltamos como elementos de carácter técnico: la incisión y el punto. Ambos se realizan sobre la pasta fresca o en estado de cuero, y suelen generar variantes básicas, ya sea por el espesor o la profundidad de las incisiones y puntos. Estas no son de orden casual, por el contrario, se escogen instrumentos más gruesos o más agudos y se profundiza con mayor o menor intensidad sobre la pasta fresca. Ello sólo con el objeto de lograr distintas texturas y contrastes visuales. Al parecer se procede como una necesidad de diferenciar los trazos y lograr la mayor cantidad de variantes dentro de los parámetros establecidos.

Otro factor importante dentro del orden técnico se manifiesta principalmente dentro del punteado. En la mayoría de casos el punteado es preciso, logrando puntos circulares de dimensiones más o menos uniformes dentro de lo escogido (punzón grueso o agudo; mayor o menor fuerza). Pero en determinadas ocasiones el punteado suelen ser sesgado o inclinado respecto al plano de trabajo. Con ello se logran puntos alargados u ovalados, con el área más profunda en uno de los extremos del punto.

Finalmente otra modalidad de punto implica clavar a profundidad el instrumento o punzón y antes de retirarlo, inclinarlo o removerlo y atraerlo hacia uno de los lados. Con ello se consigue un abultamiento de la pasta hacia el orillo del punto. Con esta técnica se obtiene una nueva variante en la textura.

De este modo, dentro de los elementos de orden técnico, incisión y punto, logramos una variedad de texturas y contrastes visuales que enriquecen el estilo a pesar de lo aparentemente limitado de la técnica.

El segundo elemento importante en la caracterización del estilo está en el diseño. Es decir, como las especificaciones técnicas antes descritas se combinan y organizan para establecer unidades formales reconocibles y con identidad propia. En primer lugar, todo diseño ejecutado en la técnica incisión y punteado -comprendida en este estilo- se desarrolla principalmente al interior de franjas horizontales definidas por el ancho de la superficie externa del gollete de ciertos cántaros y de la cara interna del cuello de determinadas ollas. Estas franjas anulares y horizontales son de distinto ancho y dimensión, y constituyen el parámetro inicial para la organización del diseño. Este se inicia con la ejecución de líneas incisas que ordenan el espacio y definen el esquema, luego los puntos sólo complementan el diseño. 
En el paso inicial se ha podido aislar el trazado de líneas en forma de zigzag simples, dobles y compuestos, ejecutados paralelos al labio de la vasija. Al parecer una variante del trazado anterior está compuesta por una suerte de arcos ojivales discontinuos pero diverge tanto del original que se le considera como un segundo modelo. Un tercer modelo de trazado lo constituyen una sucesión de rombos que pueden ser concéntricos y aspas en doble línea que cubren todo el ancho de la franja. Finalmente divergiendo un poco de los modelos anteriores -pues estas se ordenan verticalmente- hemos identificado cuatro formas típicas adicionales de representación. Por un lado tenemos el diseño de "chebrones" alineados, luego bandas verticales paralelas, diseños escalonados que penden de los labios, y finalmente banderillas escalonadas.

Dentro de este modo de ejecutar los trazos (con sus respectivas variantes) los puntos complementan el diseño y le dan cuerpo al dibujo. Consiguen dar variedad e identidad propia a diseños semejantes. En los casos más simples los puntos acompañan a las líneas ordenándose a uno o ambos lados de la misma; en otros casos se inscriben alineadamente al interior de dos líneas; en un tercer caso (el más común) conforman rellenos saturando los espacios triangulares, rómbicos, escalonados o rectangulares. En este caso su distribución suele ser desordenada pero uniforme, sin dejar espacios en blanco y en algunos casos suelen superponerse atinando a las líneas que delimitan los espacios. Ello como producto de su orden aleatorio.

En resumen tenemos principalmente diseños horizontales en forma de zigzag simple, doble, compuesto; diseños en ojival, rómbico y aspas. Mientras que en los diseños verticales predominan los escalonados, banderillas, chebrones y bandas verticales. Cada cual halla heterogeneidad en el espesor de las líneas, su dimensión particular y el espacio del cual disponen, pero principalmente en el modo como se rellenan los espacios. Sean internos o externos, alineados o aleatorios, denso o ligero, grueso o suave, orificios grandes o pequeños, sesgados o simétricos (circulares u ojivales), etc. En este contexto línea incisa y punto se conjugan y armonizan en un estilo de aparente rigidez pero de gran versatilidad.

El tercer elemento empleado en este análisis para caracterizar al estilo "Hualla" o "Inciso Punzonado en franjas" es el de la forma de las vasijas que contienen dichos diseños (Fig. 1A y 1B). Al igual que en los elementos anteriores el aspecto morfológico también presenta una relación coherente para con los diseños, ya que estos se presentan principalmente en dos formas básicas: cántaros y ollas. Lamentablemente nuestra colección sólo está compuesta por bordes bastante completos, pero no por vasijas enteras. Ello nos obligó a recurrir al catálogo de formas elaborado para el material procedente de la huaca Huallamarca y cotejarlo con nuestro material y alguna de las formas graficadas por Zegarra de la misma procedencia. Al realizar la correlación obtuvimos las siguientes formas de vajillas. En primer lugar tenemos una clase específica de cántaro (de 23 a $28 \mathrm{~cm}$. de alto) de cuerpo globular achatado, o de hombros altos y base cónica aplanada (cuerpo de trompo). En este caso se aprecia un par de asas laterales dispuestas en forma vertical, un poco por encima del ecuador de la vasija. El siguiente componente característico de este tipo morfológico es el gollete principalmente convexo, (en un caso fue aquillado) y otro de forma convexa de labios evertidos. Los diámetros varían entre los 9 y 13 cm. de abertura (Fig. 1A).

El segundo tipo morfológico corresponde a una variedad de olla de cuello medio o alto, recto y divergente. Cuyos diámetros varían entre los $16-18$ y $20-22 \mathrm{~cm}$. de boca. Una particularidad es que el diámetro del cuerpo suele ser menor o igual que el de la boca de las vasijas pequeñas, y presentan el hombros caídos y al parecer la base 


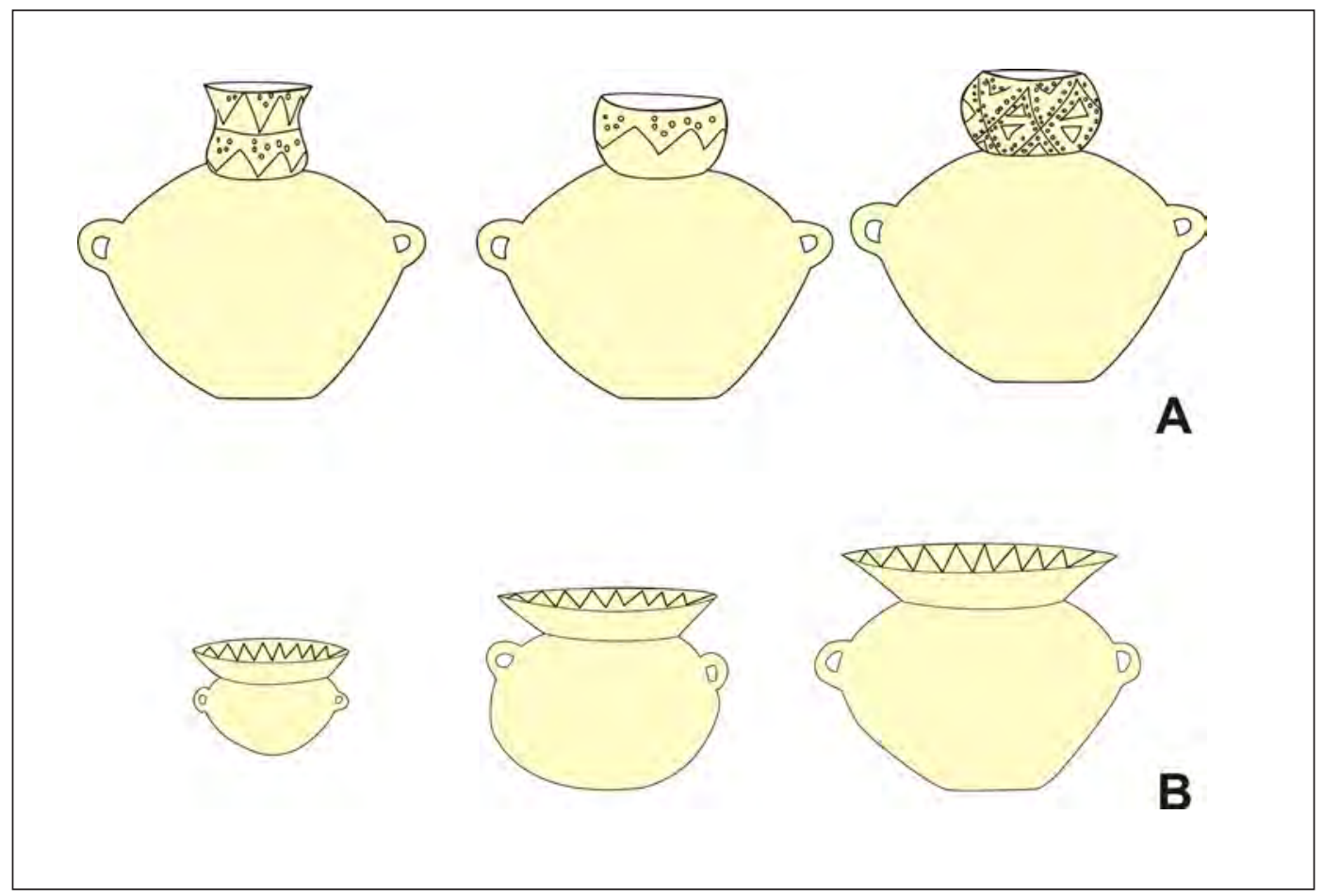

Figura 1. Estilo "Hualla" en cántaros y ollas.

cónica, posiblemente porten asas verticales en el ecuador (algunos de estos datos nos quedan aun por confirmar fuera de los dibujos de Zegarra). En las ollas de mayor tamaño el diámetro del cuerpo puede ser mayor (Fig. 1B).

Cántaros y ollas, ollas y cántaros, se complementan dentro del estilo por medio de diseños y acabados compartidos, pero también reflejan una suerte de oposición. Esta no sólo es la inherente a sus respectivas formas y funciones, sino también, a los espacios que ocupa el diseño en cada clase de vasija en particular. De este modo los cántaros se decoran en la cara externa del gollete mientras que las ollas lo hacen en la cara interna de los cuellos.

En la cara externa de los golletes predominan los diseños con posibilidad de ocupar espacios amplios como el zigzag doble, diseño ojival, rómbico, en aspas, chebrones, bandas, escalonados y banderillas, mientras que en la cara interna del cuello de las ollas predomina el zigzag simple y compuesto y en menor grado los escalonados y banderillas.

Algo propio a ambas clases de vasijas es el tipo de pasta - que si bien no se le ha trabajado en detalle - se aprecia semejanza entre ambas. Suelen ser de consistencia compacta, textura regular, color anaranjado claro (cocción oxidante), superficie alisada simple y generalmente presenta un baño lechoso de color amarillo pálido al exterior.

Este tipo de acabado constituye el cuarto elemento que nos permite caracterizar a este grupo estilístico, formal y cronológicamente. El baño amarillo pálido de la superficie externa de ambas clases de vasijas las enlaza entre sí, pero también las une cronológicamente con otra clase y género de vasijas que veremos más adelante.

Grupos morfológicos adecuadamente clasificados, modalidad de diseño con parámetros técnicos y organizacionales visiblemente esta- 
blecidos y un baño amarillo pálido aglutinante nos habla de un estilo bien definido y con identidad propia.

Variantes morfológicas de la técnica: Esta modalidad técnica y decorativa se ejecuta también en otra clase de formas de vasijas, principalmente en botellas, sean escultóricas de doble cuerpo o cara gollete. $\mathrm{Al}$ parecer su vinculación se da con ciertos personajes antropomorfos modelados en esta clase de alfarería. Así se decoran tocados o cabelleras y posiblemente también el adornen en la representación de unkus. Esta variante morfológica no se encuentra tan bien documentada aun, por lo cual no profundizaremos en sus detalles, ni la incluimos dentro del estilo Hualla.

\section{Estilo Ichma Anaranjado Ornamental}

Se trata probablemente del estilo más conspicuo de la producción local, pero no necesa- riamente el más popular. Podría equivaler al estilo propio de las élites locales y a la muestra más original de lo que se viene llamando Ichma Inicial o Temprano. Sus formas y diseños evocan un carácter suntuario, y al parecer muestra una iconografía inherente a su realidad, con elementos y colores de substrato local. Exhibe suficientes características propias como para ser denominado el estilo "Polícromo" u "Ornamental" del componente Ichma.

Este se define por la presencia activa de un color anaranjado oscuro o rojizo que cubre como fondo buena parte de la superficie de las piezas, o también puede conformar diseños menores.

Se trata de un estilo muy complejo a nivel morfológico y de diseño. Al parecer nos encontramos frente a un estilo principalmente ornamental (pictórico y escultórico), que presenta elementos decorativos más o menos estables, y el grado de combinación que muestra con otro

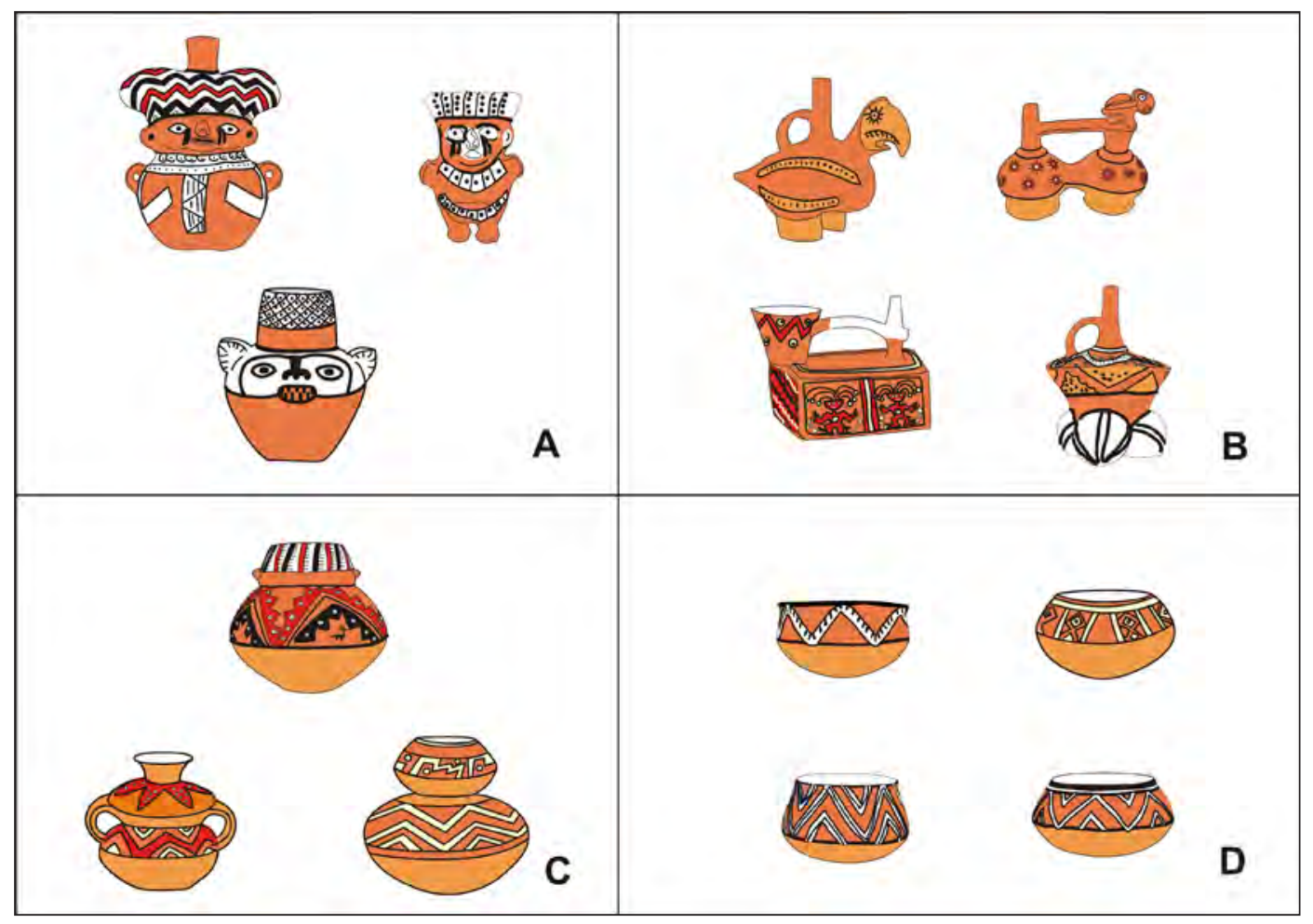

Figura 2. Estilo Ichma "Anaranjado Ornamental". 
tipo de diseños depende en parte de la forma de las vasijas que lo contengan. Por ello debido a su complejidad se puede organizar en dos grupos.

Según nuestro análisis existen dos grupos morfológicos relacionados con este tipo de decoración. Por un lado se encuentra un grupo bastante nutrido y versátil de formas simples como cuencos (convexos, aquillados, globulares, etc.), ollitas de cuello corto (Fig. 2D), cántaros y botellas de cuerpo compuesto y acombado, etc. (Fig. 2C).

Mientras que del otro lado tenemos un grupo más heterogéneo determinado principalmente por formas escultóricas modeladas, que involucra una gama de botellas antropomorfas, figurinas (Fig. 2A), botellas de doble cuerpo, botellas base en trípode, vasijas ornitomorfas modeladas, etc. (Fig. 2B). Estos dos grupos morfológicamente representados tanto por formas simples (Fig. 2C y 2D), como por una gama de vasijas escultóricas modeladas (Fig. 2A y 2B), muestran en común su carácter polícromo y suntuario, así como la preeminencia del color anaranjado rojizo.

En el análisis del diseño y la decoración también se identificaron dos subgrupos no excluyentes, que por lo general presenta correlato con las formas antes señaladas. El primer grupo decorativo esta representado por diseños en zigzag formando triángulos, grecas simples, compuestas, y rombos. Estos se ejecutan preferentemente sobre una banda horizontal de color anaranjado rojizo que circunda la vajilla, generalmente delimitada con líneas blancas o negras. Los diseños del zigzag se ejecutan con líneas de color crema y se delimitan en negro. Esta decoración básica se suele relacionar con alfarería de forma simple como cuencos, cántaros y ollitas de formas cóncavas y globulares, mientras que cuando se practica sobre botellas de formas escultóricas frecuentemente se les añaden elementos secundarios en las entrantes y salientes como círculos blancos con un punto y delinea- dos con negro, círculos radiados, puntos negros alineados al interior de las grecas y bastoncitos colgando como flecos en los laterales del zigzag etc. En algunos casos los elementos principales son acompañados por una sucesión de figuras escalonadas, que emplean como relleno un color rojo o anaranjado más oscuro.

En el segundo grupo decorativo se practica principalmente sobre vasijas escultóricas, sean botellas modeladas (zoo, fito u ornitomorfas), o figurines antropomorfos. Según sea el caso se utiliza un profuso relleno de color anaranjado rojizo como fondo, que puede ser complementado por amplios campos de color blanco.

El fondo anaranjado suele dar el color principal de las vasijas, y los diseños se realizan con líneas curvas u ondulantes de color blanco y negro, que complementan las molduras modeladas delineando rostros, atuendos, decorados y otros detalles anatómicos.

A diferencia de la superficie anaranjada que suele ser totalizadora, los campos blancos son rectangulares, trapezoidales o geométricos, $\mathrm{cu}$ briendo el área de tocados, pectorales, unkus, taparrabos etc. Así mismo, los diseños son más lineales y geométricos, formando una sucesión de líneas paralelas verticales o diagonales (rellenadas de puntos o colores) y dameros cuadrangulares o rómbicos con punto al centro. Los dameros ejecutados sobre el fondo blanco o crema, suelen ocupar grandes áreas del gollete o como paneles en el cuerpo central. Mientras que las líneas paralelas (rellenas con puntos, hondas y guiones o color) se descuelgan tanto de los labios (al interior o al exterior de las vasijas) como del bisel superior de las figurinas (en el tocado).

Junto con las barritas de puntos o colores y dameros reticulados aparecen círculos pequeños, comas y semicírculos con punto al centro sobre el fondo blanco y señalando unkus o pectorales.

En resumen, podemos formular que el estilo Ichma Ornamental (simple o escultórico) se or- 
ganiza principalmente en torno a dos subgrupos definidos por variables morfológicas y decorativas. Por un lado tenemos formas simples decoradas con grecas y rombos desarrollados sobre una banda horizontal y fondo anaranjado. Y por el otro tenemos un segundo subgrupo definido por una decoración de líneas negras y blancas realizadas sobre un fondo anaranjado y blanco en piezas escultóricas.

\section{Estilo Aquillado}

Este estilo como tal se encuentra definido casi exclusivamente por elementos formales (estilo morfológico estable), inherentes a la estructura de la vasija que lo contiene. A diferencia de otros estilos que se fundamentan principalmente en parámetros decorativos y/o técnicos, el estilo Aquillado lo hace sobre la base de elementos morfológicos bien definidos, mismos que conjugados crean variantes dentro del estilo, sin por ello perder su identidad. Así, el estilo se halla referido a una particular manera -gráfica y formal- de hacer las cosas, con parámetros formales y estéticos bien definidos, capaces de presentar una información visual y remitir al observador a su identidad y contenido.

Los elementos morfológicos que consideramos como principales para definir el estilo Aquillado son cuatro: cuerpo globular o aquillado sin asas, cuello o aquillado, anillo cóncavo y aplicación cónica. Debemos señalar sin embargo que estos parámetros no son tan rígidos y puede faltar uno u otro de los elementos, e incluso se le pueden incorporar variantes que podrían llegan a transformar radicalmente las formas tipo.

El primer elemento sobresaliente del estilo es un cuerpo globular, casi esférico, limpio en forma y sin asas. En algunos ejemplares el cuerpo globular se achata e inclusive adopta una forma carenada con un punto de inflexión agudo en el ecuador.

El segundo y principal elemento definitorio del estilo es el cuello aquillado. Este componen- te puede insinuarse muy sutilmente como un reborde anular en el cuello, o bien graficarse nítidamente con carenas sobresalientes. El cuello aquillado puede ser simple, con una carena convergente, o doble terminando en labios rectos evertidos. Nuevamente aquí se aprecian una serie de pequeñas variantes que buscan romper la monotonía y posible rigidez técnica. Por ello, varían las medidas y proporciones de las carenas (más altas o más bajas) y remarcan o atenúan la unión con el cuerpo globular, llegando incluso a presentar una continuidad formal. Sin embargo queda claro siempre que la abertura de la boca del cuello es sensiblemente menor que el diámetro máximo del cuerpo.

El tercer elemento corresponde a una suerte de anillo o collar cóncavo que articula el cuerpo globular con el cuello de la vasija. Al parecer reemplaza a las carenas definiendo formas nuevas

Una aplicación cónica como cuarto elemento, es característico del estilo. Corresponde a un pequeño añadido cuneiforme agudo. Estos conitos de arcilla suelen ser pegados sobre el cuello (en las salientes de la carena) o bien en el tercio superior del cuerpo. Se pueden aplicar de a uno, en pares opuestos, grupos de a dos o en gran número alineados sobre la carena. Su forma es muy característica y sólo se presenta como componente exclusivo de este estilo.

La suma y combinación de estos elementos originó tres grupos morfológicos, pero principalmente una clase peculiar de ollas que puede ser el prototipo morfológico del estilo (Fig. 3A). El género definido como ollas globulares de cuello aquillado con aplicaciones cónicas, que engloba una serie de variantes que sólo enriquecen el estilo.

Un segundo grupo morfológico está definido por pequeños cuencos con o sin cuello, de cuerpo globular o aquillado. Son formas muy básicas que sólo llevan la aplicación en el cuerpo (Fig. 3B).

Un tercer grupo podría definirse como cántaros pequeños, en los que el cuello aquillado 


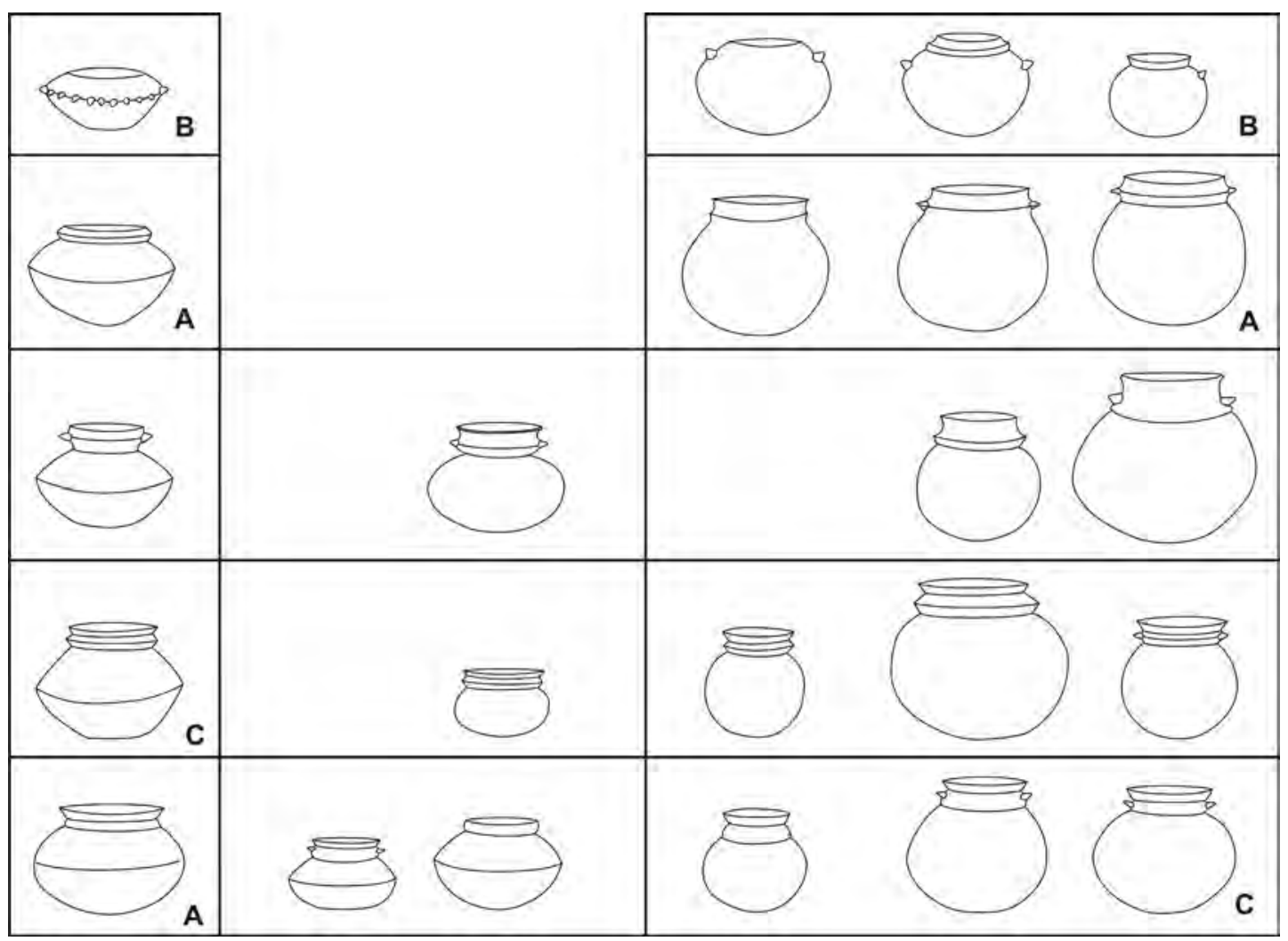

Figura 3. Estilo Ichma "Aquillado" en ollas.

alto es bastante más angosto que el diámetro mayor del cuerpo. Un grupo importante de ellos incorpora el anillo cóncavo estrangulando el cuello. La aplicación se suele pegar en el anillo, que para tal efecto reemplaza a la carena. Es probable que este género de cántaros provea la mayor cantidad de cuerpos globulares achatados y aquillados (Fig. 3C).

Variantes morfológicas del estilo: En este apartado presentamos cuatro nuevos grupos morfológicos emparentados con la estructura formal antes descrita. Los nuevos especimenes utilizan sólo uno o dos de los elementos característicos del estilo e incorporan nuevos elementos morfológicos, llegando incluso a transformando radicalmente el modelo inicial.

El cuarto grupo está definido por pequeñas ollitas globulares con anillo cóncavo por cuello, sin aquillado, sin aplicaciones y con una o dos asas laterales en el cuerpo (Fig. 4A).

El quinto grupo se define en base a una heterogeneidad de ánforas que conjugan muy bien diversos elementos. Estas llevan en común el cuerpo esférico ligeramente achatado o aquillado, con asas laterales verticales sobre el ecuador en algunos casos estas se reemplazan por aplicaciones cónicas dispuestas en pares (verticales u horizontales). El empleo casi exclusivo de una base con pedestal, y finalmente la utilización del anillo cóncavo en el cuello y/o borde evertido. Otra innovación en este grupo de vasijas corresponde a una suerte de repisa o reborde biselado en el extremo superior del cuerpo limitando el cuello. Este tipo de ánforas que incorporan el reborde biselado final, al parecer tendrán una larga duración (Fig. 4B).

El sexto grupo está compuesto por dos ejemplares de cántaros de cuello evertido con 

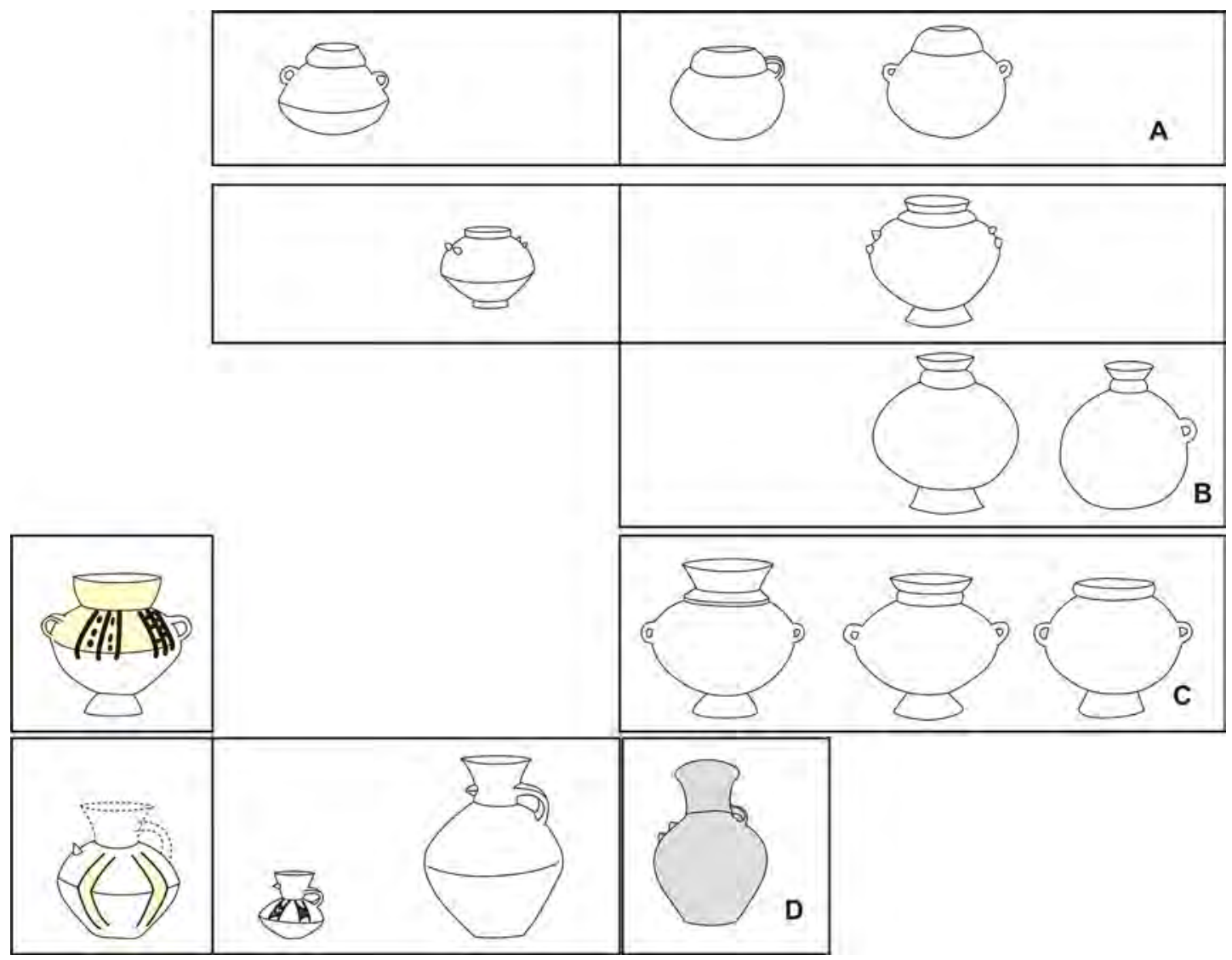

Figura 4. Estilo Ichma "Aquillado" en cántaros, urnas y jarras.

anillo cóncavo angosto y cuerpo globular. Uno presenta un asa y el otro una base con pedestal. Ambos guardan mucha semejanza con las ánforas antes descritas pero de cuello mucho más angosto (Fig. 4C).

Por último, el séptimo grupo está representado por jarras de distintos tamaños, de cuerpo aquillado, base plana, gollete evertido unido al cuerpo en su parte media por un asa cintada, y en el extremo opuesto una pequeña aplicación cónica, ya sea en el gollete o en el tercio superior del cuerpo (Fig. 4D).

\section{Formas simples y complejas en alfarería ordinaria}

Dentro de la categoría formas simples se catalogan dos clases principales de vasijas, ollas y cántaros. Las ollas corresponde al género más numeroso de vasijas y se puede subdividir en dos grupos, por un lado ollas de asa vertical y del otro ollas de asa horizontal. El primer grupo presenta la menor variabilidad en su forma. Es de cuerpo globular simple, con cuello recto y medio divergente. Las asas son pequeñas, cilíndricas y se ubican en el tercio superior del cuerpo sobre el ecuador. Las diferencias más visibles entre unas y otras se producen en el tamaño, que varían desde muy grande, grande, medianas y pequeñas (Fig. 5). Sin embargo otras diferencias menos evidentes corresponden a aspectos y tendencias relativas a la proporción. Es decir que cuanto más alto y menos evertido sea el cuello de la vasija, el cuerpo puede ser más ovoide. Del otro lado en tanto más amplio y bajo sea el cuello el cuerpo es relativamente 

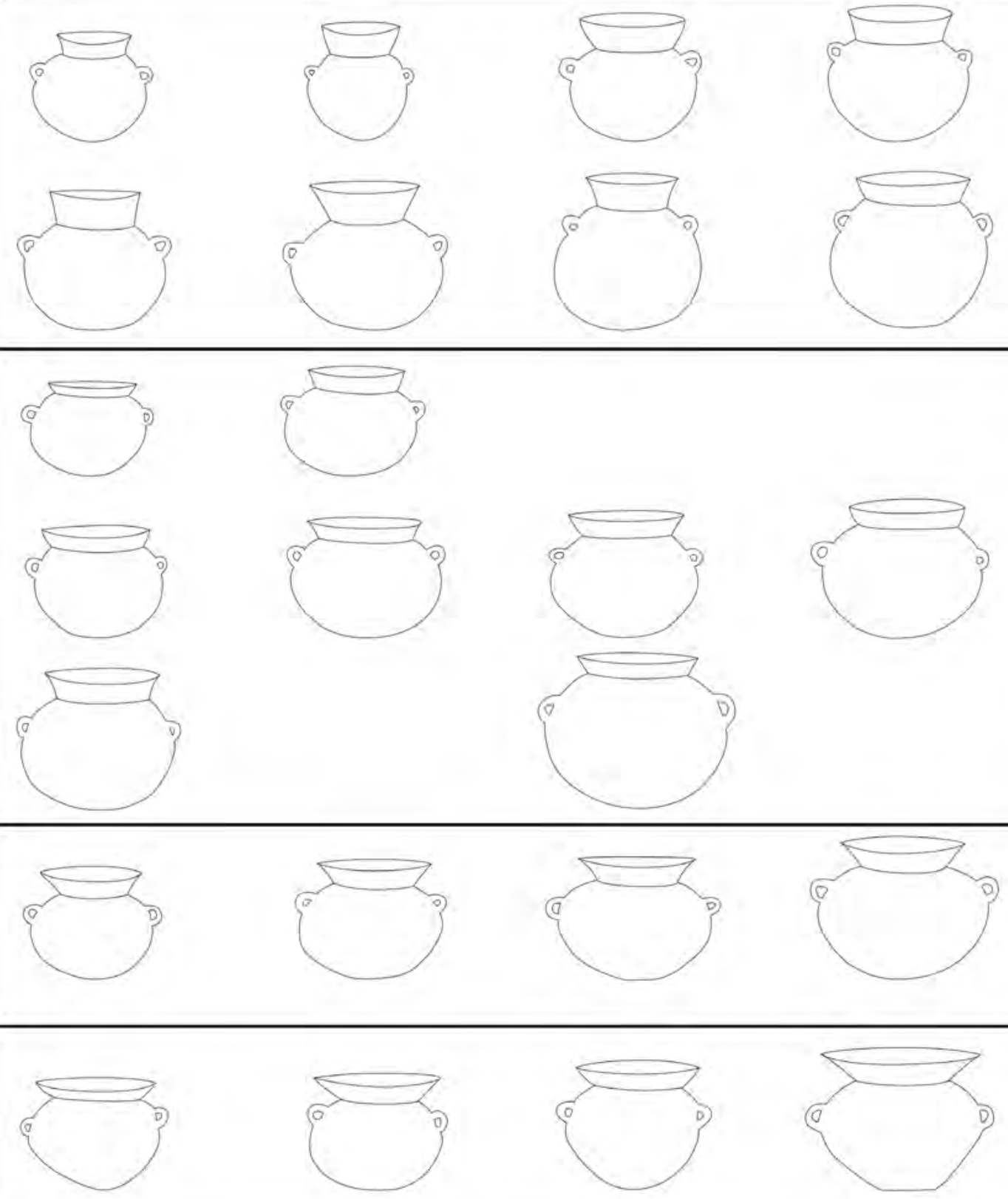

Figura 5. Estilo Ichma "Ordinario" en ollas de asa vertical.

más globular. Finalmente en tanto más abierto y evertido o divergente sea el cuello, el cuerpo será más achatado. Dentro de este grupo podríamos diferenciar un conjunto morfológico menos numeroso que corresponde a vasijas de cuello y borde alto y muy evertido, cuyo cuerpo tiende a ser achatado u ovoide pero de base cónica. Y a diferencia del los anteriores posiblemente el diámetro máximo del cuerpo sea menor al diámetro de la boca de la vasija. Estas característi- 
cas particulares la separan del grupo y podrían emparentarla con las ollas del estilo Inciso Punzonado en franjas.

Otro subgrupo de este género podría corresponder a un tipo de ollas de cuerpo achatado (en algunos casos aquillado) de base cónica, con bordes rectos divergentes y asas verticales que unen el labio o la parte media del cuello con la parte superior del cuerpo. Posiblemente sea más tardía o revista mayor duración en el tiempo.

Sólo en muy pocas ollas se ha podido percibir decoración pintada, por el contrario la presencia de gruesas capas de hollín en superficie son indicadoras de un uso plenamente utilitario. Pero cuando la decoración se halla presente es del tipo crema chorreado.

El segundo grupo dentro de la categoría de ollas corresponde a las ollas con asas horizontales. Y como ya se mencionó, a diferencia del grupo anterior, estas cuantitativamente se hallan en menor número, pero presentan la mayor variabilidad de formas. Existen ollas de hombro alto, cuerpo alargado y base cónica, con cuello corto que puede ser recto, ligeramente everti- do, cóncavo o cóncavo con labios divergentes. Las asas se ubican en el tercio o cuarto superior, muy cerca del cuello. Algunos de estos ejemplares muestran pintura crema chorreado. Posiblemente también sea una variedad más tardía o revista mayor duración en el tiempo (Fig. 6).

Otro subgrupo corresponde a un tipo de ollas de cuello corto recto, cóncavo o divergente pero de cuerpo globular. El tercer subgrupo esta representado por ollas de cuello recto y divergente de cuerpo achatado y base cónica. Nuevamente existen variantes de los subgrupos anteriores pero de cuerpo aquillado.

La segunda clase de vasija a tratar corresponde a cántaros, que compete a una categoría mucho menos numerosa pero igual de rica. Al igual que la categoría anterior se paramos los cántaros en dos grupos principales unos con asa vertical y los otros con asa horizontal. Mayor detalle de ambos géneros será tratado en otra oportunidad.

Como ya se adelantó sólo un pequeño porcentaje del total de las vasijas de formas simples u ordinarias se encuentra decorado, y el estilo decorativo preferente es el Crema Chorreado en

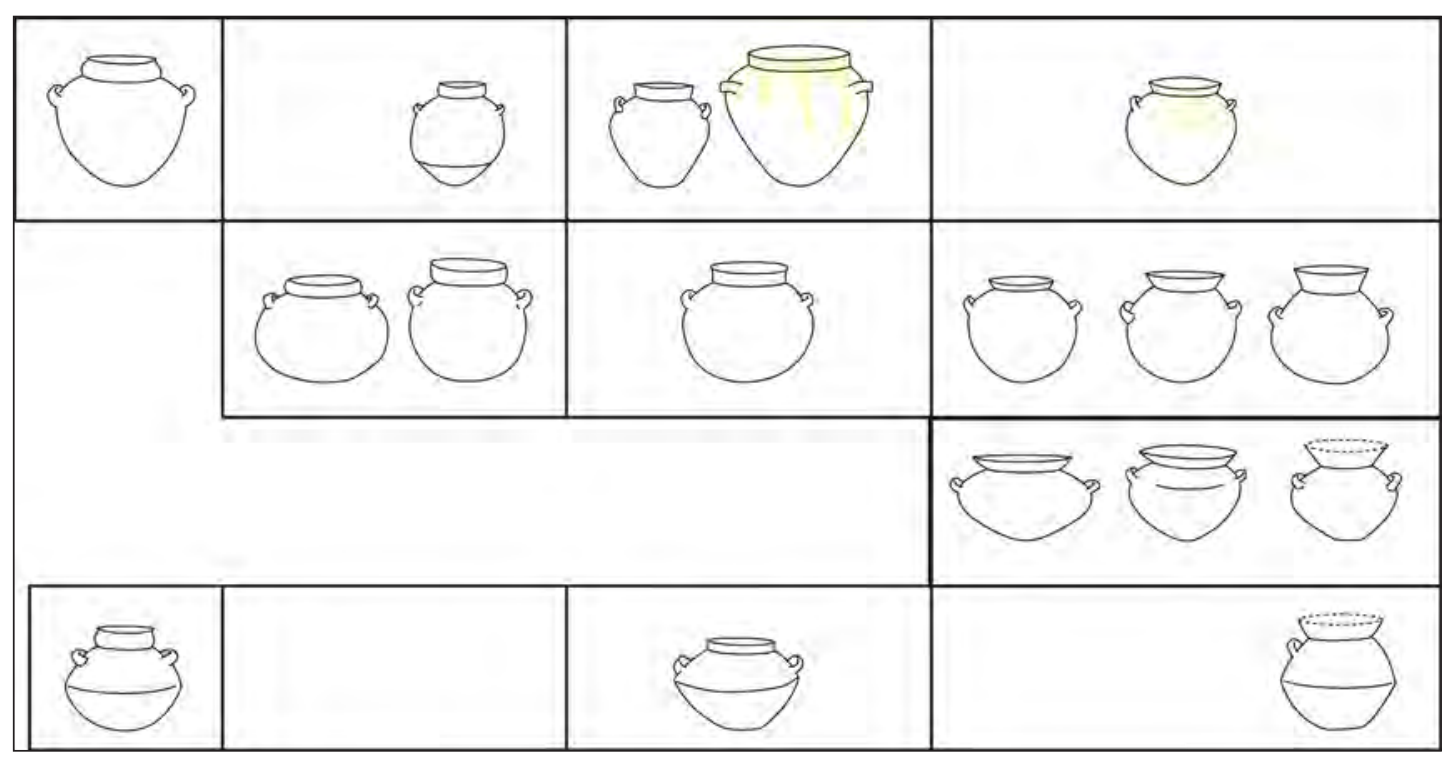

Figura 6. Estilo Ichma "Ordinario" en ollas de asa horizontal. 


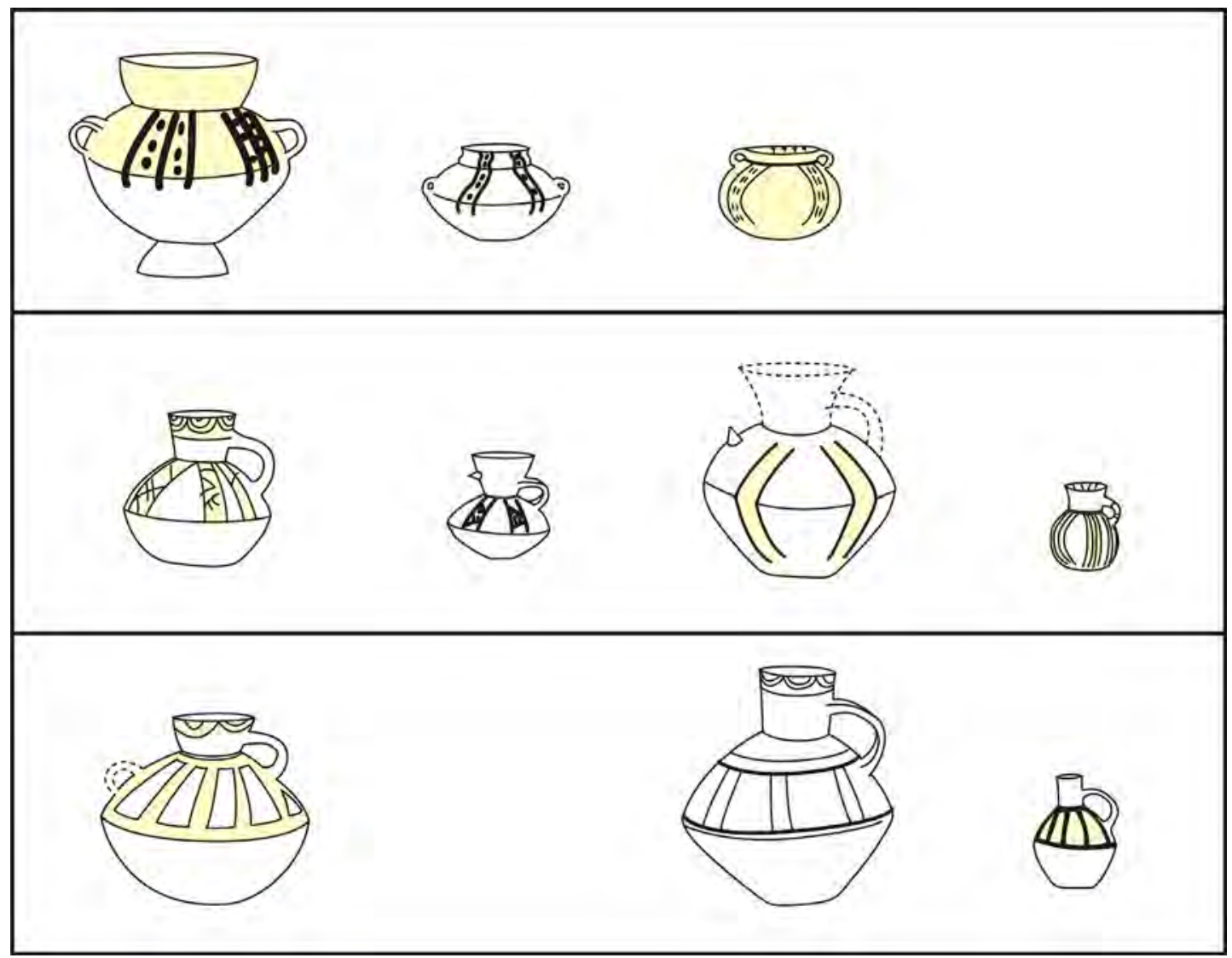

Figura 7. Estilo Ichma "Negro sobre Crema" y otros.

bandas horizontales sobre el labio, cuello y asas, o en franjas verticales radiadas en la mitad superior del cuerpo. Posiblemente algunas formas hallan sido favorecidas con el estilo decorativo Amarillo Pálido, mediante un baño total o parcial, sin embargo, por el momento no tenemos un registro explicito.

\section{Estilo Negro sobre Crema}

Se trata de uno de los estilos mejor estudiados y más profusamente documentados. Corresponde a un estilo pictográfico, que emplea normas bastante precisas para la ejecución de sus diseños. Su ejecución comienza principalmente por aplicar un engobe crema sobre el cuello y campo superior del cuerpo globular o aquillado de las vasijas. Sobre este se ejecutan diseños geométricos en líneas negras. Como norma se delimitan franjas paralelas y verticales descolgadas del cuello de los recipientes, y al interior se practican trazos entrelazados o puntos y guiones alineados. Otra modalidad consiste en elaborar sólo franjas verticales radiadas de color crema sobre la superficie del cuerpo, y sobre ellas se bosquejan los trazos antes señalados. Finalmente como complemento a ambas modalidades, los cuellos suelen ser decorados por blondas semicirculares concéntricas o círculos seccionados (Fig. 7).

Al igual que todos los estilos calificados como transgresores no se asocia a una forma en particular que le sea exclusiva, aunque guarda preferencia por ánforas y jarras del estilo Aquillado, ollitas pequeñas variadas y sobre todo 
cántaros de cuerpo globular y gollete compuesto y acombado.

\section{Estilo Crema Chorreado}

Al igual que el anterior se trata de uno de los estilos mejor estudiados por otros autores, e implica un estilo decorativo definitivamente transgresor para esta fase. No se le relaciona con un grupo morfológico alfarero en particular, por el contrario, su modo diseño más o menos estable puede irrumpir casi en cualquier forma estilística, simple o compleja (Fig. 8).

Al tratarse de un estilo pictográfico compromete a un engobe crema blanquecino que se aplica mediante gruesos brochazos bastante desprolijos. Estos se realizan principalmente sobre el labio de las vasijas generando un chorreo, alrededor del cuello, sobre o circundando las asas, o mediante trazos verticales en el cuerpo de las vasijas motivando una suerte de franjas radiadas. Este estilo se diferencia del "Amarillo
Pálido" en el color (más claro y cremoso) pero principalmente en la forma de aplicación.

Las formas en las cuales se suele presentar son de lo más variadas, y al igual que el estilo "Negro Pulido", también compromete e irrumpe sobre una variedad de estilos morfológicos. Se puede presentar sobre piezas del estilo Aquillado (sean ánforas y cántaros), del Marrón Cóncavo (principalmente cántaros) y sobre una variedad de ollas, botellas y cántaros simples compuestos de la alfarería ordinaria. Al parecer hacia el Ichma Medio y Tardío este estilo establece una relación más estrecha con la alfarería ordinaria y será aplicada sobre una base roja oscura.

\section{Estilo Amarillo Pálido}

Este estilo decorativo se caracteriza por ser bastante simple, consiste en aplicar un baño de engobe aguado, de color amarillo pálido sobre toda la superficie de la vasija sobre la cual se trabaja. El baño suele ser uniforme y en algunos

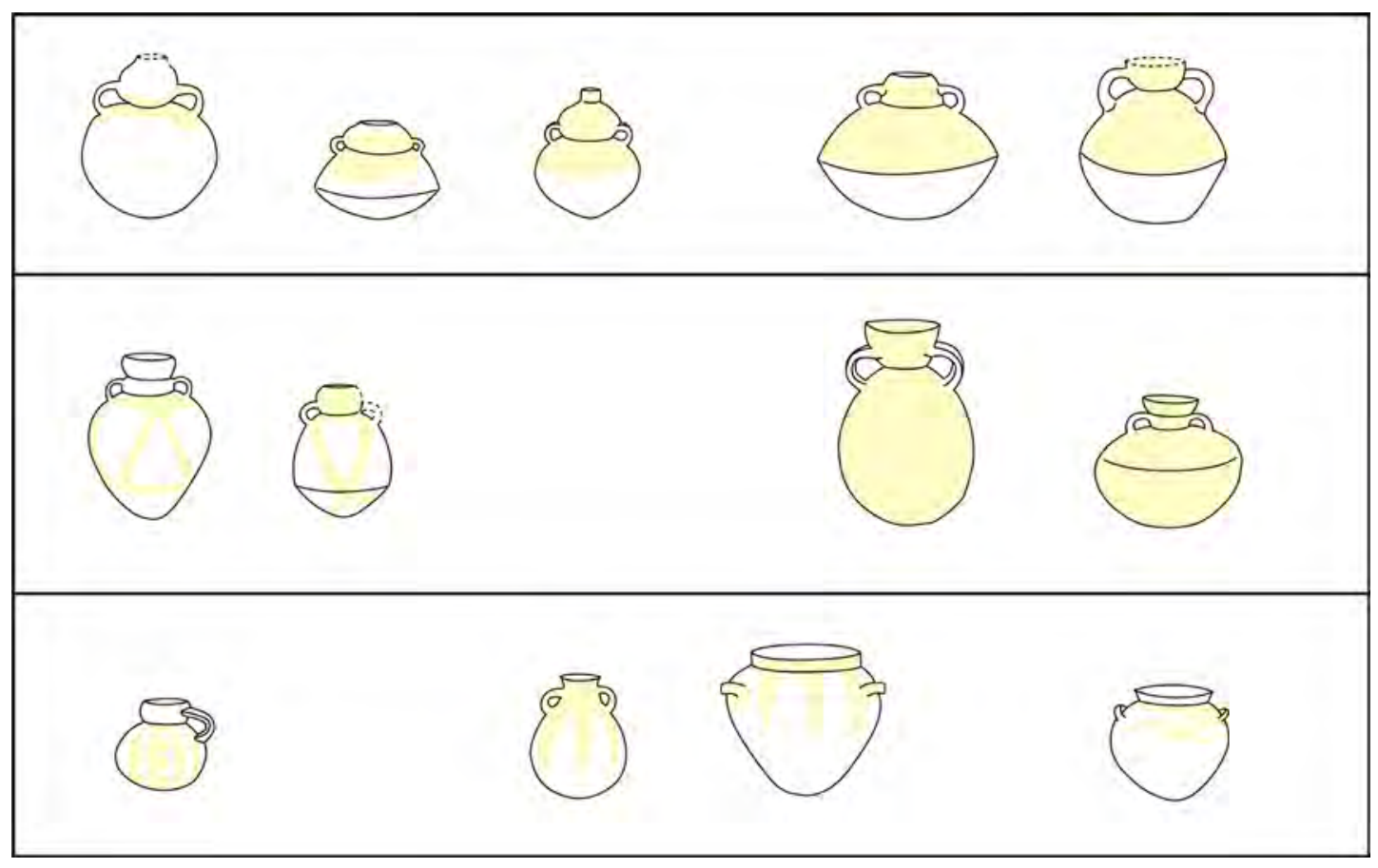

Figura 8. Estilo "Crema Chorreado" y "Amarillo Pálido". 
casos involucra la parte interna de los cuellos (Fig. 8). Se trata de una técnica decorativa que compromete a una variedad de formas siendo las mejor documentadas las que se relacionan con el estilo Inciso Punzonado en franjas (cántaros y ollas). Lamentablemente no contamos con un registro más completo y preciso de formas alternas para definir mejor el estilo, sin embargo, los fragmentos analizados nos hablan de vasijas de gran formato como cántaros y tinajas, sin embargo, su caracterización morfológica más detallada está aun por estudiar.

\section{Estilo Negro Pulido}

Esta categoría estilística se define en función de un solo elemento componente decorativo, que es exclusivamente de orden tecnológico. Se trata de un proceso de cocción reductora, mediante el cual se obtienen piezas de color negro oscuro. Frecuentemente las piezas alfareras han sido previamente pulidas antes de la cocción, razón por la cual, tras esta adquieren un brillo mayor. Al parecer este estilo tan distintivo y de naturaleza estrictamente técnica, no se halla relacionado a una forma particular de vasijas, como sucede con los otros estilos, por el contrario, esta técnica decorativa se practica sobre una gran variedad de formas, irrumpiendo en los demás estilos morfológicos generando variantes enriquecedoras al interior de cada cual. La cocción reductora como técnica decorativa aparece en casi todas las épocas de la historia de la cerámica prehispánica de la costa central, por lo cual, su relación cronológica sólo se podría identificar en función a un determinado tipo de pasta, posición estratigráfica y tratamiento o forma particular.

Esta técnica estilística se ha identificado en piezas del estilo Aquillado, tanto en ollas de cuello aquillado, como en ánforas y jarras. También se aprecia en cántaros de cuerpo compuesto, vasos y copas con pedestal anular y en botellas de pico aflautado.

\section{Discusión}

Uno de los principales temas de discusión en la actualidad para los períodos tardíos de la costa central es el referido al del origen y componentes formales del estilo Ichma.

Tanto Guerrero como Vallejo (al igual que Menzel y Ravines en su momento) señalan que hacia fines del Horizonte Medio habría existido una fuerte relación entre las zonas de HuauraChancay y Rímac-Pachacamac. De este modo, los antiguos estilos del Horizonte Medio de la costa norcentral habrían impregnado su identidad en la conformación de los posteriores estilos locales de las cuencas bajas de los ríos Huaura y Rímac, conformando así los estilos Chancay e Ichma respectivamente.

Uno de los indicadores foráneos más utilizados para sustentar esta afirmación sería la presencia del estilo Tricolor Geométrico en el Rímac. Sin embargo, como señalamos en un documento preparado anteriormente acerca de las particularidades de este estilo en Huallamarca, concluíamos en su carácter casi restringido como pieza de intercambio y valoración exclusivamente ritual y funeraria. En segundo lugar, a nuestro entender, su alcance y repercusión en el Rímac no fue tan grande, llegando sólo a identificársele a plenitud y en poca escala -sólo en Huallamarca- y en contextos exclusivamente funerarios. Finalmente, por las particularidades tan rígidas del estilo se determinó también que mucho del material frecuentemente asignado en la bibliografía local como perteneciente a esta categoría no responde realmente a su identidad.

En el mismo sentido, otro indicador al parecer importante para establecer esta relación (Huaura-Huacho y Rímac-Pachacamac) se sustenta en la tan frecuente y recurrida banda crema con semicírculos pendientes del borde a manera de blonda. A diferencia del anterior, este elemento -que en el Tricolor Geométrico se presenta sólo como uno más de los elementos accesorios o secundarios- en el Rímac se populariza y llega 
a conformar un elemento decorativo muy distintivo, pero como ya lo señalamos, se encuentra dentro de la categoría de estilo transgresor, es decir, no fija identidad sobre una forma cerámica definida, por el contrario irrumpe sobre una variedad de tipos morfológicos casi indistintamente. Al parecer se trató sólo de un elemento fácil de reproducir y que halló rápida acogida. Su significado y carácter simbólico probablemente no fueron asimilados.

A pesar de ello, se puede apreciar que en efecto existió una relación de intercambio con la costa norcentral, prolongando antiguas redes, pero que no necesariamente marcó el inicio o influyó significativamente en la formación del estilo local. Pues con el mismo criterio podríamos atribuir y sobreestimar la importancia de los estilos Lambayeque (Huaco Rey), Estampado, Chancay, Chincha o Ica, cuyos ejemplares o diseños se hallan presentes en Huallamarca y la costa central en calidad de piezas de intercambio. Evidenciando un espectro costero mucho más amplio de contactos y para el intercambio. Por el contrario debemos orientarnos a buscar "el origen" del estilo Ichma en los antecedentes locales.

Como todo parece indicar que no fueron exclusivamente los factores externos los que posibilitaron el cambio estilístico hacia el Ichma Inicial. Más aun, pensamos que la esencia de su origen se encontraría en formas y fenómenos de raigambre local. Entonces, ipor qué a nivel estilístico el Ichma Inicial es tan diferente del Lima Tardío y los estilos subsiguientes? Y por el contrario iporqué guarda algunas semejanzas con los estilos de la costa norcentral?

Con respecto a la primera pregunta pareciere que algunos estilos del Ichma Inicial se hubieren desarrollado sólo sobre la base de los estilos domésticos o no decorativos locales. Al parecer, ello le habría impreso un marcado carácter localista, con la pérdida casi completa de los antiguos paradigmas y cánones estilísticos previos que distinguían a la vieja clase dirigente y a una sociedad compleja organizada de forma estatal. La ruptura con un orden establecido habría potenciado la emergencia de nuevas y particulares formas de expresión, donde las nuevas y/o antiguas élites también buscaron afianzar sus identidades particulares. En este contexto el Ichma Inicial muestra identidades propias y regionales.

En segundo lugar, como ya explicamos, las aparentes semejanzas estilísticas para con la costa norcentral se debería a la sobreestimación de los tipos decorados con respecto a los no decorados, y al hallazgo de piezas de intercambio. Sin embargo, podemos constatar que existiría un estilo ornamental de raigambre local, cuyo carácter escultórico lo presentarían como el más conspicuo del Ichma Inicial. El estilo Anaranjado Ornamental tiende a representar personajes civiles ricamente ataviados, variedad de aves, frutos, posiblemente peces, mamíferos y una variedad decorada sobre formas simples. Este estilo se identifica además por la vivacidad de colores, su policromía, y característico color anaranjado rojizo.

Particularizando la discusión sobre este grupo estilístico observamos que su componente morfológico en vasijas escultóricas modeladas, nos remiten a los alfares escultóricos y modelados algo más tempranos de la costa central, posiblemente como parte de una misma tradición. Pero a diferencia de ellos, el predominante color anaranjado rojizo proviene del pigmento aplicado decorativamente sobre la superficie y no como característica distintiva de la pasta. Algunas formas de botellas con base de trípode (Fig. 2B); de cuerpo rectangular con doble pico y asa puente y personajes antropomorfos escultóricos (Fig. 2A), presentan muestras probables de antecedentes locales (Shady 1982; Guerrero y Palacios 1994).

Otro punto a particularizar a polemizar es que en la bibliografía actual se da cuenta del hallazgo de fragmentos de cerámica decorada con puntos e incisiones practicados sobre pasta fresca. De ellos, cada autor los nomina tipológicamente 
haciendo referencia a la técnica decorativa y tipo de pasta (Eeckhout 2004, Shimada 2004, Franco 2004, Vallejo 2004, etc.). Lamentablemente esto no ayuda mucho para su clasificación estilística, y la referencia cronológica se ciñe a mostrar su posición estratigráfica y en el mejor de los casos el fechado correspondiente. A pesar de ello el problema taxonómico persiste. La técnica de incidir y punzar sobre la pasta fresca en la costa central es tan antigua como la cerámica, por ello es necesario caracterizar bien cada uno de sus componentes formales y organizacionales, a fin de categorizar el estilo. Como toda intervención técnica su valoración cronológica e individualización estilística sólo se podrá lograr a partir de su relación con otros elementos morfológicos y parámetros decorativos, en desmedro de los tipológicos y en asociación de los estratigráficos.

En muchos casos materiales tipológicamente iguales o similares pueden responder a complejos estilísticos y cronológicos completamente diferentes. Y para ello debemos tener presente que ni la técnica ni la cualidad de los materiales hacen necesariamente al estilo. Por el contrario la organización, composición de elementos e identificación de cánones de diseño pueden llegar a ser más relevantes para la definición cronológica, filiación de contenidos étnicos, de significantes, de alcances y delimitación estilística y espacial. En este contexto el estilo Hualla o Inciso Punzonado en franjas responde a una categoría clasificatoria local muy particular.

Con respecto al estilo Aquillado (nombre que nos fuera propuesto por Bazán en reemplazo de Carenado) hallamos la mejor muestra de un estilo exclusivamente morfológico, de manufactura simple que logra una gran diversidad sobre la base de unos pocos elementos formales. $\mathrm{Al}$ parecer se trata de una categoría estilística que cronológicamente resulta muy característica del Ichma Temprano. Bazán publica una foto del desaparecido sitio Conde de las Torres, en la que se aprecia material correspondiente a estas caracte- rísticas, siendo coherente además en el tipo de fardos y modo de enterramiento. El también las asigna dentro del Ichma Inicial, pero los posiciona cronológicamente en la época 3 del HM (Bazán 1998: 32).

\section{Conclusiones}

En la producción de cada estilo cerámico del Ichma Inicial, se percibe la imperiosa necesidad de individualizar a cada pieza o vasija como un ejemplar único, pero sin perder la unicidad del estilo. Salvo para el caso de la alfarería de tipo ordinaria, generalmente ninguna pieza repite las mismas características morfológicas o decorativas en su integridad. Por el contrario, la conjugación de los diversos elementos componentes tiende a buscar su particularidad y exclusividad.

En el desarrollo simultáneo de varios grupos estilísticos con características propias, se aprecia un gusto por la variedad o individualización de la identidad personal, llegado incluso a admitir la incorporación o copia de elementos iconográficos foráneo con un afán distintivo. Podemos observar dentro de la aparente homogeneidad que ofrecen un montón de piezas burdas y de poca o ninguna decoración, una clara disposición al desarrollo de identidades individuales.

La producción de cerámica en manos de especialistas al parecer permitió desarrollar una suerte de catálogo o inventario de formas y decoraciones que impedían la repetición no programada de piezas, y a la par, mantener la unidad de cada grupo estilístico. Cada especialista o talles tendría la habilidad y responsabilidad de no duplicar formas, con la finalidad de garantizar a sus consumidores el carácter exclusivo de su adquisición.

Lamentablemente aún distamos mucho de conocer los valores simbólicos, sociales o funcionales de cada estilo. Lo particular de su organización interna, y si cada grupo estilístico fue desarrollado por un taller diferente, o si un mismo grupo de artesanos producía y procesaban 
simultáneamente toda una variedad de estilos. Además, de cuáles fueron los componentes distintivos de cada grupo social, laboral, étnico, territorial, etc.

\section{Bibliografía}

Bazán Del Campo, Francisco

1990 Arqueología y etnohistoria de los períodos prehispánicos tardíos de la costa central del Perú. 256 p. Tesis de licenciatura en arqueología, Facultad de Ciencias Sociales, Universidad Nacional Mayor de San Marcos, Lima.

1998 Guía de Lima, circuito arqueológico. 96 p. Centro de Investigaciones para el Desarrollo de la Cultura Andina, Lima.

Eeckhout, Peter

2004 La sombra de Ychsma. Bulletin de l'Institut Français d' Etudes Andines, 33 (3): 403-423. Institut Français d' Études Andines. Lima.

Franco, Régulo

2004 Poder religioso, crisis y prosperidad en Pachacamac: del Horizonte Medio al Intermedio Tardío. Bulletin de l'Institut Français d' Etudes Andines, 33 (3): 465-506. Institut Français d' Études Andines. Lima.

Guerrero, Daniel

2004 Cronología cerámica y patrones funerarios del valle del Rímac: una aproximación a los períodos tardíos. En. Villacorta (ed.). Puruchuco y la sociedad de Lima: un homenaje a Arturo Jiménez Borja. 157 - 177 p. Lima.

Kaulicke, Peter

1997 Contextos funerarios de Ancón. Esbozo de una síntesis analítica. 125 p. Fondo Editorial de la Pontificia Universidad Católica del Perú, Lima.
2000 La sombra de Pachacamac: Huari en la costa central. En: Boletín de Arqueología PUCP. 4: 313 - 358 p. Pontificia Universidad Católica del Perú Lima.

Ravines, Rogger

1977 Prácticas funerarias en Ancón, primera parte. Revista del Museo Nacional, XLIII 327 - 397 p. Lima.

1981 Prácticas funerarias en Ancón, segunda parte. Revista del Museo Nacional. XLV 89 - 166 p. Lima.

Shimada, Izumi; Segura; Rostworowski; Watanabe

2004 Una nueva evaluación de la Plaza de los Peregrinos de Pachacamac: aportes de la primera campaña 203 del Proyecto Arqueológico Pachacamac. Bulletin de l'Institut Français d' Etudes Andines, 33 (3): 507-538. Institut Français d'Études Andines. Lima.

Uhle, Max

1991 Pachacamac. Shimada (ed.) University Museum of Archaeology and Anthropology. 103 p. University of Pennsylvania, Philadelphia.

Vallejo, Francisco

2004 El estilo Ychsma: características generales, secuencia y distribución geográfica. Bulletin de l'Institut Français d'Etudes Andines, 33 (3): 595-642. Institut Français d' Études Andines. Lima.

Willey, Gordon

1943 A supplement to the pottery sequence at Ancon. Archeological studies in Peru. 1941 - 1942, New York 